\title{
Scavenger Receptor Class B Type 1 Deletion Led to Coronary Atherosclerosis and Ischemic Heart Disease in Low-density Lipoprotein Receptor Knockout Mice on Modified Western-type Diet
}

\author{
Jiawei Liao', Xin Guo ${ }^{1}$, Mengyu Wang ${ }^{1}$, Chengyan Dong ${ }^{2,3}$, Mingming Gao ${ }^{1}$, Huan Wang ${ }^{1}$, \\ Abudurexiti Kayoumu ${ }^{1}$, Qiang Shen ${ }^{1}$, Yuhui Wang ${ }^{1}$, Fan Wang ${ }^{2,3,4}$, Wei Huang ${ }^{1}$ and George Liu ${ }^{1,4}$ \\ ${ }^{1}$ Institute of Cardiovascular Sciences and Key Laboratory of Molecular Cardiovascular Sciences, Ministry of Education, Peking \\ University Health Science Center, Beijing, China \\ ${ }^{2}$ Interdisciplinary Laboratory, Institute of Biophysics, Chinese Academy of Sciences, Beijing, China \\ ${ }^{3}$ Medical Isotopes Research Center, Peking University Health Science Center, Beijing, China \\ ${ }^{4}$ Center for Molecular and Translational Medicine, Peking University Health Science Center, Beijing, China
}

\begin{abstract}
Aim: Atherosclerosis-prone apolipoprotein E (apoE) or low-density lipoprotein receptor (LDL-R) knockout $(\mathrm{KO})$ mice are generally resistant to developing coronary atherosclerosis $(\mathrm{CA})$ and ischemic heart disease (IHD). However, studies have demonstrated the occurrence of spontaneous CA and IHD in scavenger receptor class $\mathrm{B}$ type $1(\mathrm{SR}-\mathrm{BI}) / \mathrm{apoE}$ double $\mathrm{KO}(\mathrm{dKO})$ mice, which suggests that SR-BI could be a potential target for the prevention and therapy of CA and IHD. This possibility was later investigated in SR-BI/LDL-R dKO mice, but no signs of CA or IHD was identified when mice were fed a normal western-type diet. Here we explored whether SR-BI deletion could result in CA and IHD in LDL-R KO mice when fed a modified western-type diet containing higher $(0.5 \%)$ cholesterol. Methods: Cardiac functions were detected by electrocardiography, single photon emission computed tomography (SPECT), echocardiography (Echo) and 2,3,5-triphenyltetrazolium chloride staining. $\mathrm{CA}$ was visualized by hematoxylin-eosin staining.

Results: After 12 weeks on the modified diet, SR-BI/LDL-R dKO mice developed cardiac ischemia/ infarction, together with systolic dysfunction and left ventricular dilatation. CA was most severe at the aortic sinus level to an extent that no dKO mice survived to 20 weeks on the modified diet. None of control mice, however, developed CA or IHD.

Conclusions: SR-BI deletion led to CA and IHD in LDL-R KO mice when fed the modified westerntype diet. We established SR-BI/LDL-R dKO mice as a diet-induced murine model of human IHD and developed detection methods, using a combination of SPECT and Echo, for effective in vivo evaluation of cardiac functions.
\end{abstract}

Key words: Scavenger receptor class B type 1, Coronary atherosclerosis, Ischemic heart disease

Copyright@2017 Japan Atherosclerosis Society

This article is distributed under the terms of the latest version of CC BY-NC-SA defined by the Creative Commons Attribution License.

\section{Introduction}

The prevalence of ischemic heart disease (IHD) has grown rapidly around the world in the last 50

Address for correspondence: Wei Huang, Institute of Cardiovascular Sciences and Key Laboratory of Molecular Cardiovascular Sciences, Ministry of Education, Peking University Health Science Center, Beijing, China

E-mail: huangwei@bjmu.edu.cn

Received: September 12, 2015

Accepted for publication: May 9, 2016 years. According to recent reports by the World Health Organization, IHD is currently the leading cause of mortality in developed countries and will acclaim the most lives in the coming future ${ }^{1)}$. Thus, appropriate disease models are in urgent need for extensive studies on the pathological mechanisms of the disease as well as for the development of effective preventive and therapeutic approaches. Since the introduction of atherosclerosis-prone apolipoprotein $\mathrm{E}$ (apoE) knockout $(\mathrm{KO})^{2,3)}$ and low-density lipoprotein receptor (LDL$\mathrm{R}) \mathrm{KO}$ mice $^{4,5)}$ in 1992 and 1993, respectively, mice 
have been the most widely used animal models for studying atherosclerotic diseases. However, atherosclerosis in mice was mainly distributed in the aorta, whereas coronary atherosclerosis (CA) and IHD were rather rare ${ }^{6,7)}$.

Scavenger receptor class B type 1 (SR-BI) is a cell-surface high-density lipoprotein (HDL) receptor that is associated with reverse cholesterol transport (RCT) and plays a vital role in the systemic homeostasis of cholesterol. The deletion of SR-BI in mice disrupts the process of RCT and leads to HDL abnormalities, including the accumulation of free cholesterol, enlargement of HDL particles, and enrichment or loss of bio-active proteins carried on the surface of HDL particles ${ }^{8,9)}$. Hence, the deletion of SR-BI leads to accelerated atherosclerosis ${ }^{10)}$. In addition, even the loss of SR-BI resulted in spontaneous obstructive CA and myocardial infarction in apoE $\mathrm{KO}$ mice ${ }^{11)}$, suggesting that SR-BI could be a potential target for the prevention and therapy of CA and IHD. However, in another study, atherosclerotic LDL-R KO mice with SR-BI deletion failed to develop CA and IHD when fed a western-type diet ${ }^{12)}$. As such, whether the modulation of susceptibility to the development of CA and IHD by SR-BI is apoE-dependent or -independent remains unknown. Here we explored if SR-BI deficiency could lead to CA and IHD in LDL-R KO mice when fed a modified western-type diet with higher cholesterol content than that used in normal westerntype diet.

\section{Methods}

\section{Animals and Diet}

SR-BI KO and LDL-R KO mice were supplied by Peking University Experimental Animal Center and crossbred to generate SR-BI/LDL-R dKO mice. Modified western-type diet (see Supplemental Table 1) containing $0.5 \%$ cholesterol (AMRESCO, USA) and $20 \%$ fat were fed to 10 - to 12 -week-old SR-BI/LDL-R $\mathrm{dKO}$ mice and age-matched control LDL-R KO mice. All mice included in the experiment were females. The housing, care, and all the experimental procedures were conducted following the regulations of the National Institute of Health and approved by the Animal Care Committee at Peking University.

\section{Plasma Lipids Analysis}

Blood samples were collected by retro-orbital venous plexus puncture after mice were fasted for $4 \mathrm{~h}$. Plasma total cholesterol (TC) and triglycerides (TG) were measured using commercial kits (BioSino, China). Plasma HDL-cholesterol (HDL-C) was measured with the same kit for TC assay after plasma sam- ples precipitated with $20 \%$ polyethylene glycol solution to remove apoB-containing lipoproteins. For the analysis of lipoprotein distribution, pooled plasma samples from 4-5 mice of the same group were fractioned by fast protein liquid chromatography (FPLC) as previously reported ${ }^{13)}$.

Electrocardiography (ECG), Single Photon Emission Computed Tomography (SPECT), and Echocardiography (Echo) Analysis

ECG, SPECT, and Echo were obtained under anesthetization with $1.5 \%$ isoflurane inhalation. ECGs were obtained using four needle electrodes in each of the limbs with a multiple physiological signal recording system (Chengdu Instrument Factory, China). SPECT images were acquired at $40 \mathrm{~min}$ after the intravenous administration of $37.0 \mathrm{MBq}(1.0 \mathrm{mCi})$ of ${ }^{99 \mathrm{~m}} \mathrm{Tc}$-MIBI with nanoScan (Mediso, Hungary). Echo images were obtained with a high-resolution Vevo 770 imaging system (VisualSonics Inc., Canada). Left ventricle (LV) dimensions and wall thicknesses were determined using parasternal short axis $\mathrm{M}$-mode images at the level of the papillary muscle and averaged from three cardiac cycles. Ejection fraction (EF), fractional shortening (FS), and LV volume were calculated using the Vevo770 software.

\section{Myocardial 2,3,5-triphenyltetrazolium Chloride (TTC) Staining}

Mice were sacrificed and their hearts were quickly removed, stored at $-20^{\circ} \mathrm{C}$ for $30 \mathrm{~min}$ and sliced into 5-6 slices ( $2 \mathrm{~mm} / \mathrm{slice})$ from the apex towards the auricle. The slices were then incubated in $1 \%$ TTC (Sigma, USA) at $37^{\circ} \mathrm{C}$ for $15 \mathrm{~min}$. Images were taken by a digital camera (Sony, Japan).

\section{CA Analysis}

Mice were sacrificed and flushed with $20 \mathrm{ml} 0.01$ $M$ phosphate buffer solution through the LV. The hearts were harvested, fixed in 4\% paraformaldehyde solution for $4 \mathrm{~h}$ and stored in $20 \%$ sucrose solution overnight. After these preparations, the hearts were embedded in paraffin and cross-sectioned $(5 \mu \mathrm{m} /$ slice $)$ from the level of the aortic sinus to the papillary muscle at an interval of $300 \mu \mathrm{m}$. For each heart, six levels were obtained and analyzed individually. Atherosclerotic plaques were visualized by hematoxylin-eosin (HE) staining. The severity of CA was divided into four degrees defined as: none ( $<5 \%$ stenosis), $<50 \%$ stenosis $(5 \%-50 \%$ stenosis), $>50 \%$ stenosis $(50 \%-$ $95 \%$ stenosis), and occlusion ( $>95 \%$ stenosis). Data were presented as the percentage of the number of coronary arteries with the same degree of CA severity to the total number of coronary arteries. 


\section{Myocardial Histological Analysis}

Once SR-BI/LDL-R dKO mice on the modified western-type diet died, their hearts were collected, fixed in $4 \%$ paraformaldehyde solution for $6 \mathrm{~h}$, and stored in $20 \%$ sucrose solution overnight. The hearts were then embedded in paraffin and cross-sectioned as described above. Sirius red staining was applied to visualize potential fibrotic scars in the myocardium. Control hearts from LDL-R KO mice on the modified westerntype diet for 20 weeks were prepared in the same way.

\section{Statistical Analysis}

Data were presented as mean \pm standard error of the mean (SEM). Statistical significance was evaluated by Student's $t$-test, and a $P$ value $<0.05$ was regarded as significant.

\section{Results}

\section{Premature Death in SR-BI/LDL-R dKO Mice on the Modified Western-type Diet}

After 10 weeks on the modified western-type diet, $\mathrm{dKO}$ mice began to die suddenly. In fact, no $\mathrm{dKO}$ mice survived to week 20 on the modified western-type diet, while no deaths were recorded in the age-matched LDL-R KO controls (Fig.1). The median time of death for $\mathrm{dKO}$ mice on the modified western-type diet was 98 days. Autopsies conducted on the $\mathrm{dKO}$ mice that died prematurely showed that their hearts were significantly enlarged (Fig. 2A) and the mass of their hearts was almost twice that of their LDL-R KO controls that were sacrificed after 20 weeks on the modified western-type diet (Fig. 2B-C). Myocardial Sirius red staining of the $\mathrm{dKO}$ mice that died prematurely revealed the presence of massive fibrotic scars (Fig. 2D-G). Therefore, our data suggest that $\mathrm{dKO}$ mice that were fed the modified western-type diet may have suffered from myocardial infarction and heart failure.

\section{Cardiac Ischemia and Infarction in SR-BI/LDL-R dKO Mice on the Modified Western-type Diet}

We used ECG, SPECT, and myocardial TTC staining to evaluate the cardiac blood supply in mice that were fed the modified western-type diet. Before the modified western-type diet was served, the ECG of the $\mathrm{dKO}$ mice showed no significant abnormalities in the ST segment. After 12 weeks on the modified western-type diet, approximately 50\% (five in 11 mice) of the surviving dKO mice showed ST segment elevation or depression in their ECGs (Fig. 3A). ST segment changes in the ECG indicated that these $\mathrm{dKO}$ mice may have suffered cardiac ischemia/infarction, which was later confirmed by both SPECT scanning

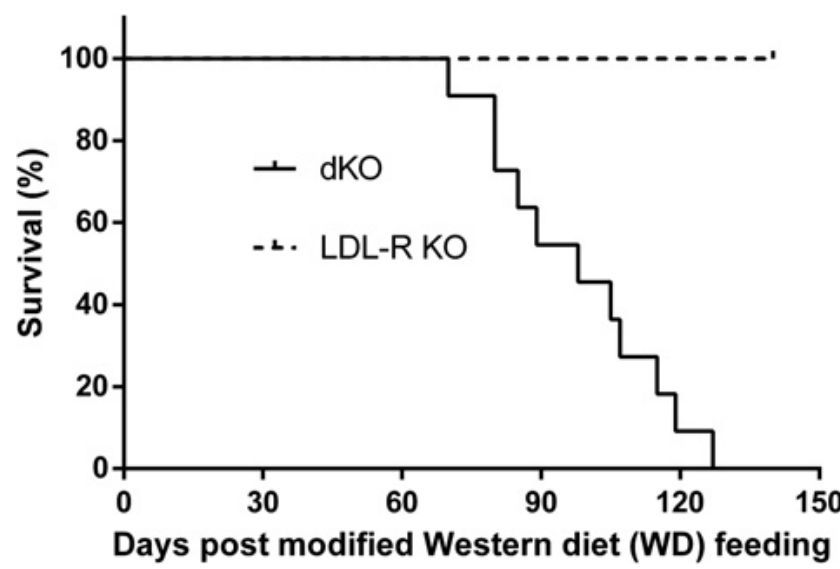

Fig. 1. Kaplan-Meier survival curve of mice on the modified western-type diet (mWD)

(Dashed line: LDL-R KO mice, $n=9$; Solid line: $\mathrm{dKO}$ mice, $n=11$ )

(Fig.3B-C) and myocardial TTC staining (Fig. 3D). In contrast, no signs of cardiac ischemia/infarction, shown either in ECG and SPECT or by TTC staining, were identified in LDL-R KO controls (Fig. 3).

\section{Heart Dysfunction in SR-BI/LDL-R dKO Mice on the Modified Western-type Diet}

Before feeding the mice with the modified western-type diet, no significant differences of the main cardiac parameters measured by Echo were identified between $\mathrm{dKO}$ and LDL-R KO mice (Fig. $\mathbf{4}$ and Table 1). After 12 weeks on the modified western-type diet, the heart rates of $\mathrm{dKO}$ mice increased significantly when compared with those of their LDL-R KO controls (Table 1). In addition, EF and FS declined while end systolic LV internal diameter and volume increased significantly in $\mathrm{dKO}$ mice, indicating systolic dysfunction and LV dilation (Fig. 4 and Table 1). Data collected from Echo demonstrated that the modified western-type diet induced heart dysfunction in $\mathrm{dKO}$ mice.

\section{CA in SR-BI/LDL-R dKO Mice on the Modified Western-type Diet}

In $\mathrm{dKO}$ mice fed the modified western-type diet for 12 weeks, atherosclerotic lesions could be found in more than $50 \%$ of the coronary arteries at the aortic sinus level. Of the lesional coronary arteries, approximately $21.7 \%$ were totally occluded, $17.4 \%$ were more than half-occluded, and only $13.0 \%$ were less than half-occluded (Fig. 5B and 5D-E). At the papillary muscle level, however, CA was significantly reduced as compared with that at the aortic sinus level, with only $5.3 \%$ of the coronary arteries being more than half occluded and $7.0 \%$ being less than half 
A.

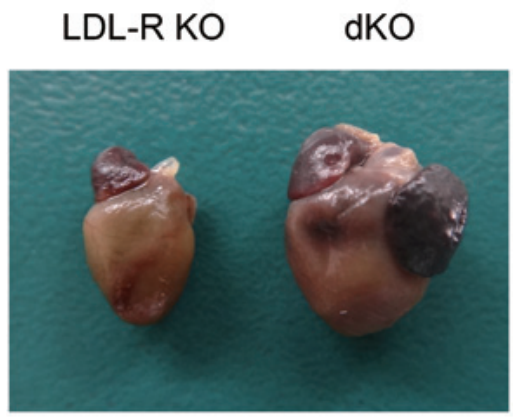

LDL-R KO

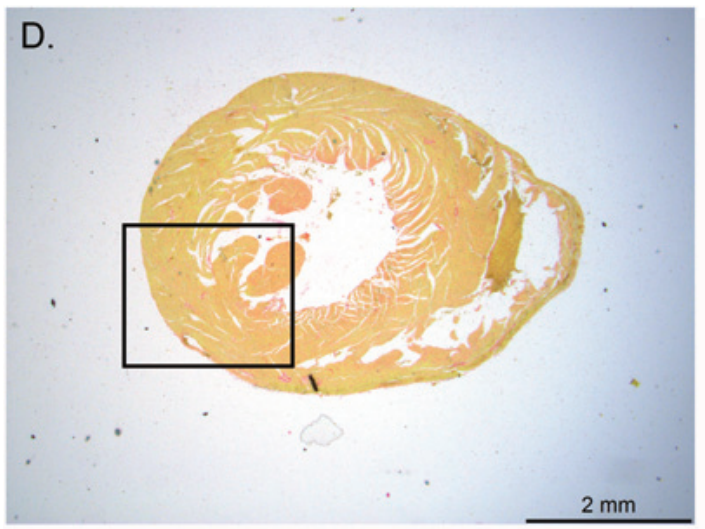

\section{F.}

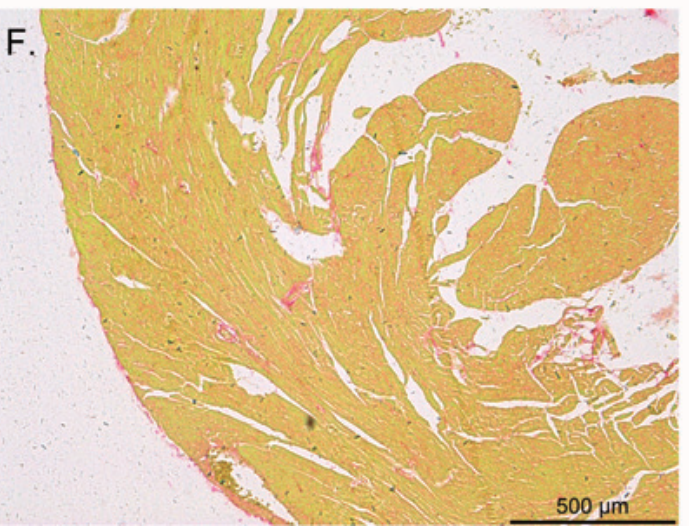

B.

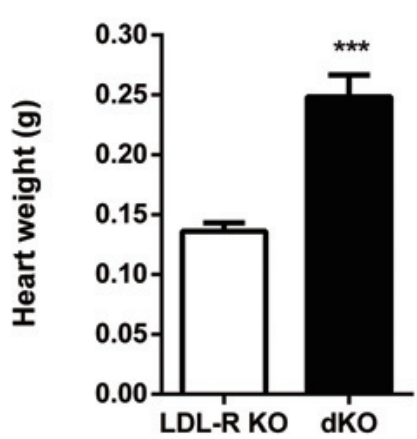

C.

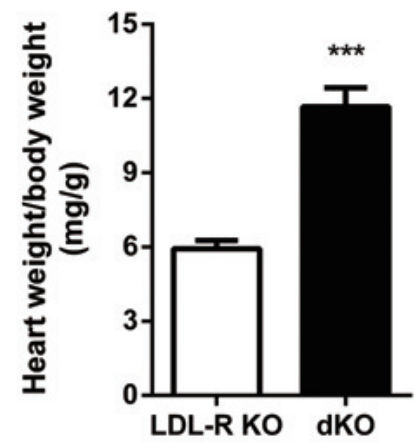

dKO
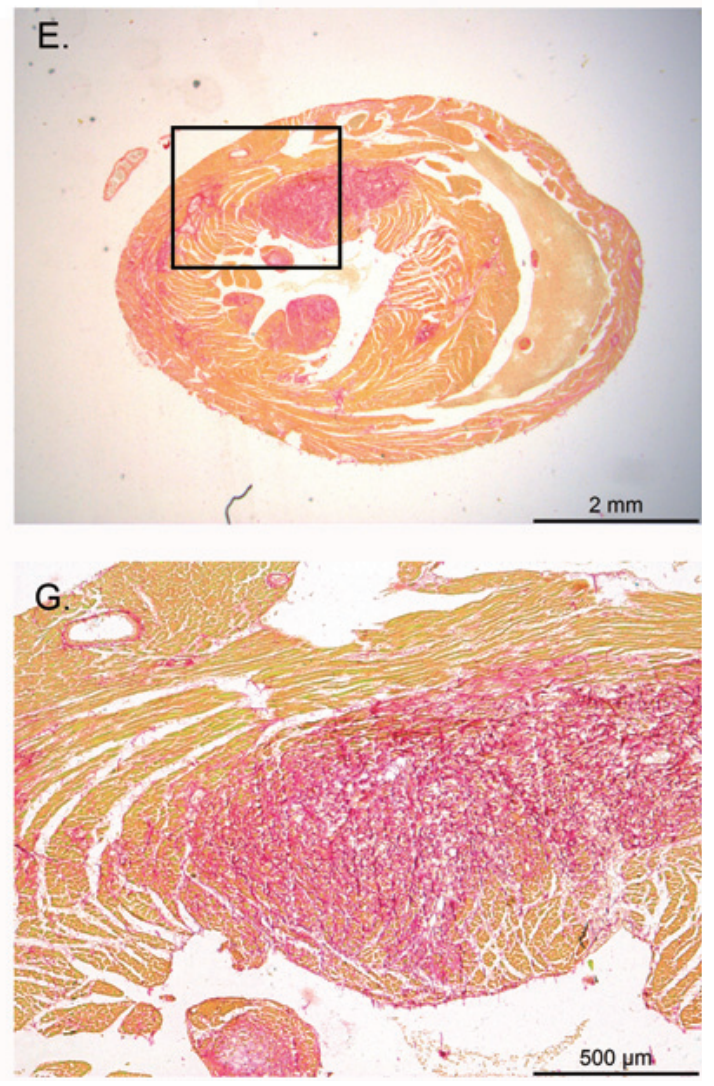

Fig. 2. Analysis of the hearts from $\mathrm{dKO}$ mice that died prematurely and LDL-R KO mice on the modified western-type diet (mWD) for 20 weeks

A: Appearance of the hearts. B and C: Gravimetric analysis of the hearts. B: Comparison of heart mass between $\mathrm{dKO}$ and control LDL-R KO mice. C: Comparison of heart mass to body weight between $\mathrm{dKO}$ and control LDL-R KO mice. D-G: Sirius red staining of the myocardium in $\mathrm{dKO}$ and control LDL-R KO mice. Normal myocardium was stained yellow, whereas fibrous tissue was stained red. F and G: Magnified views of the box areas in $\mathrm{D}$ and $\mathrm{E}$, respectively.

occluded (Fig. 5F). CA at the other four levels between the aortic sinus and the papillary muscle were quite similar to that of the papillary muscle level (data not shown). In contrast, coronary arteries in LDL-R KO controls were clear, with no atherosclerotic lesion either at the aortic sinus level (Fig. 5A, 5C, and 5E) or the papillary muscle level (Fig. 5F).

Plasma Lipids of SR-BI/LDL-R dKO Mice on the Modified Western-type Diet

Before being put on the modified western-type diet, SR-BI/LDL-R dKO mice displayed twice the 
A.

pre mWD

post mWD
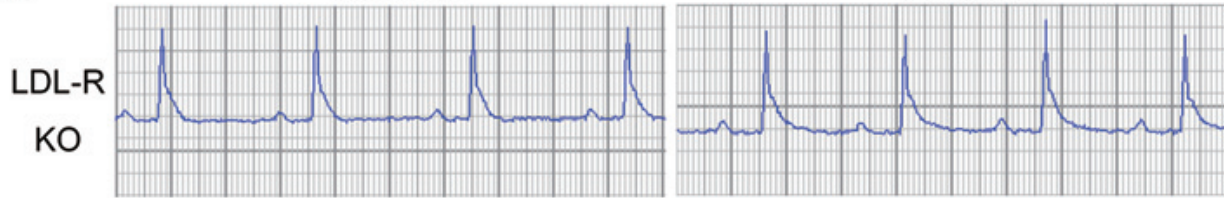

dKO
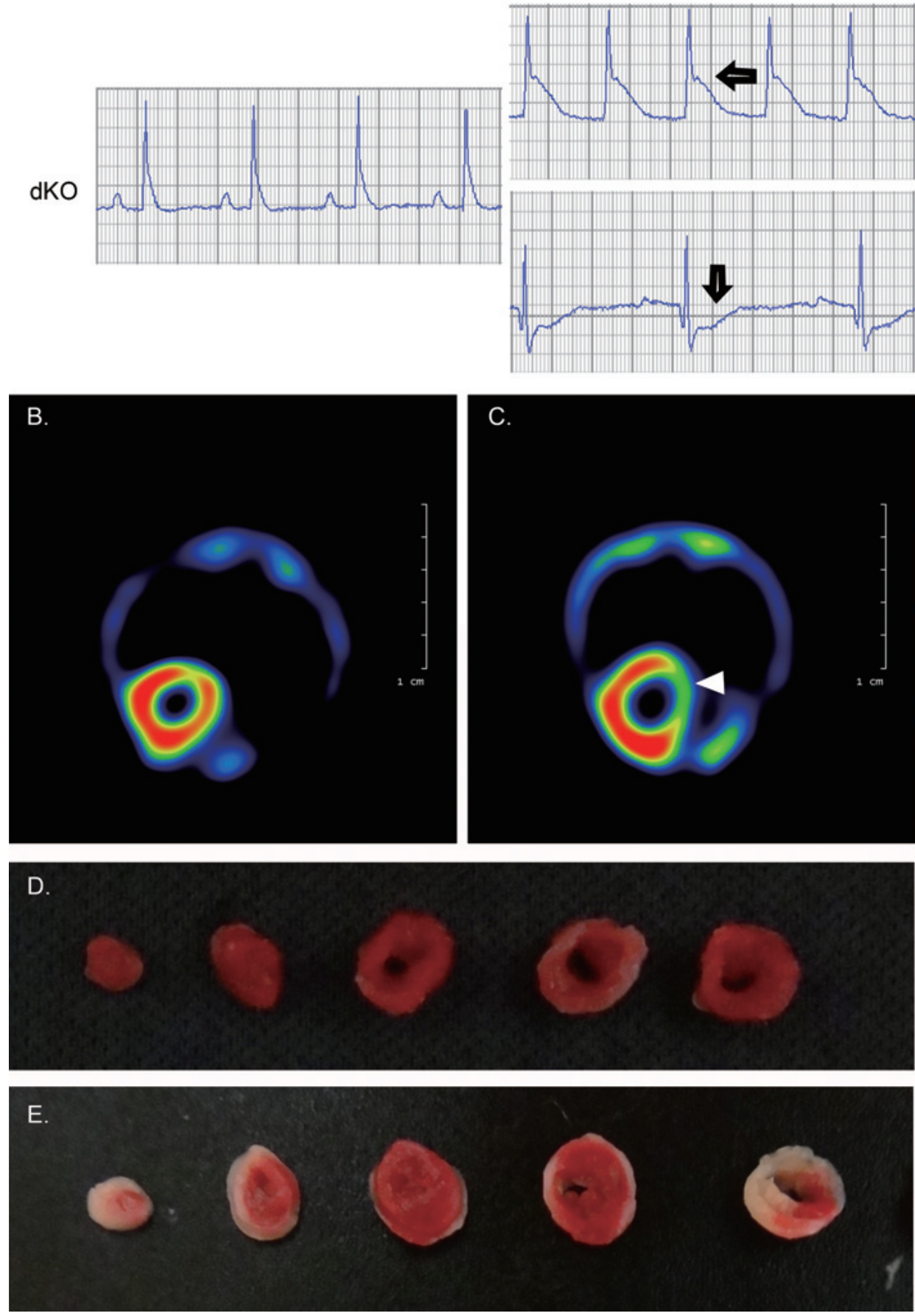

Fig. 3. ECG, SPECT, and myocardial TTC staining in mice before and after the modified western-type diet (mWD) feeding A: Representative ECG images obtained from LDL-R KO and dKO mice before and 12 weeks after mWD feeding. The arrow indicated ST segment elevation/depression. B-C: Representative myocardial SPECT images obtained from LDL-R KO (B) and dKO mice (C) on the $\mathrm{mWD}$ for 12 weeks. The triangle indicated myocardium with low blood perfusion. E: Representative images of myocardial TTC staining obtained from LDL-R KO (D) and dKO mice (E) on the mWD for 12 weeks. Normal myocardium was stained red while infarcted myocardium white. 

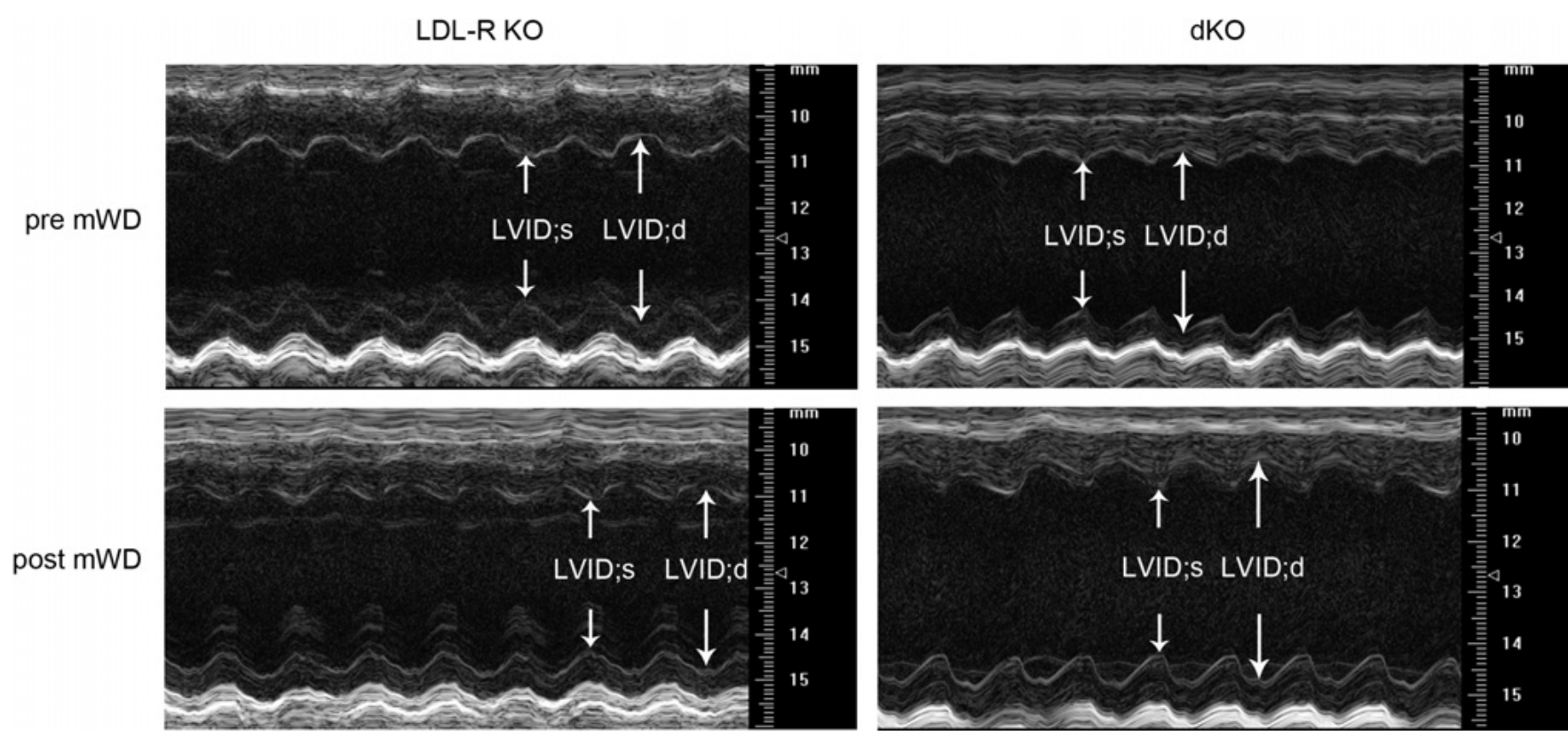

Fig. 4. Representative M-mode short axis views of the LV in mice before and after the modified western-type diet (mWD) feeding

Table 1. Echocardiographic analysis of mice before and after the modified western-type diet (mWD) feeding

\begin{tabular}{|c|c|c|c|c|}
\hline & \multicolumn{2}{|c|}{ pre mWD } & \multicolumn{2}{|c|}{ post mWD } \\
\hline & LDL-R KO & $\mathrm{dKO}$ & LDL-R KO & $\mathrm{dKO}$ \\
\hline HR (bpm) & $398 \pm 27.4$ & $400 \pm 33.3$ & $415 \pm 7.04$ & $457 \pm 11.8{ }^{*}$ \\
\hline LVID;d (mm) & $4.16 \pm 0.11$ & $4.11 \pm 0.07$ & $4.09 \pm 0.13$ & $4.22 \pm 0.09$ \\
\hline LVID;s (mm) & $2.61 \pm 0.07$ & $2.57 \pm 0.05$ & $3.03 \pm 0.12$ & $3.44 \pm 0.13, *$ \\
\hline LV Vol;d $(\mu \mathrm{L})$ & $76.9 \pm 4.82$ & $74.7 \pm 3.01$ & $74.5 \pm 5.38$ & $79.7 \pm 3.88$ \\
\hline LV Vol;s $(\mu \mathrm{L})$ & $24.9 \pm 1.64$ & $23.9 \pm 1.12$ & $36.3 \pm 3.20$ & $49.3 \pm 4.47$, $^{*}$ \\
\hline $\mathrm{EF}(\%)$ & $67.5 \pm 1.57$ & $67.8 \pm 1.74$ & $51.2 \pm 3.00$ & $38.7 \pm 2.99, *$ \\
\hline FS (\%) & $37.2 \pm 1.23$ & $37.5 \pm 1.38$ & $26.0 \pm 1.84$ & $18.7 \pm 1.61, *$ \\
\hline
\end{tabular}

Data were presented as mean \pm SEM.

mWD: modified western-type diet; HR: heart rate; LV: left ventricle; ID: internal diameter; d: diastole; s: systole; Vol: volume; EF: ejection fraction; FS: fractional shortening

*: $P<0.05$ vs. LDL-R KO mice. $n=4-6$ per group

level of plasma TC $(427 \pm 23.1 \mathrm{mg} / \mathrm{dl}$ in $\mathrm{dKO}$ mice vs. $222 \pm 9.58 \mathrm{mg} / \mathrm{dl}$ in LDL-R KO mice) and HDL-C $(188 \pm 14.4 \mathrm{mg} / \mathrm{dl}$ in $\mathrm{dKO}$ mice vs. $87.0 \pm 2.90 \mathrm{mg} / \mathrm{dl}$ in LDL-R KO mice), compared with control LDL-R KO mice (Fig. 6A and 6C). FPLC showed that plasma cholesterol was mainly distributed in LDLs and HDLs in both $\mathrm{dKO}$ and LDL-R KO mice (Fig. 6D). No difference in plasma TG $(129 \pm 6.88 \mathrm{mg} / \mathrm{dl}$ in $\mathrm{dKO}$ mice vs. $126 \pm 5.38 \mathrm{mg} / \mathrm{dl}$ in LDL-R KO mice) was observed between the two groups (Fig. 6B). After 12 weeks on the modified western-type diet, plasma TC in both LDL-R KO and $\mathrm{dKO}$ mice increased significantly. However, compared with an estimated four-fold increase of plasma TC (from basal $222 \pm 9.58 \mathrm{mg} / \mathrm{dl}$ to
$817 \pm 43.3 \mathrm{mg} / \mathrm{dl}$ ) in LDL-R KO mice, there was only a two-fold increase of plasma TC in $\mathrm{dKO}$ mice (from basal $427 \pm 23.1 \mathrm{mg} / \mathrm{dl}$ to $895 \pm 57.5 \mathrm{mg} / \mathrm{dl}$ ). These increases led to similar plasma TC levels between LDL-R KO and dKO mice on the modified westerntype diet (Fig. 6A). FPLC showed that the increase of plasma TC was mainly distributed in very low-density lipoprotein (VLDL) fractions in both mice on the modified western-type diet (Fig. 6E). As for plasma HDL-C, there was a significant decrease (from $188 \pm$ $14.4 \mathrm{mg} / \mathrm{dl}$ to $106 \pm 8.34 \mathrm{mg} / \mathrm{dl})$ in $\mathrm{dKO}$ mice, in contrast to an increase (from basal $87.0 \pm 2.90 \mathrm{mg} / \mathrm{dl}$ to $152 \pm 9.39 \mathrm{mg} / \mathrm{dl}$ ) in the LDL-R KO mice (Fig. 6C). In addition to plasma $\mathrm{TC}$, the modified western-type 

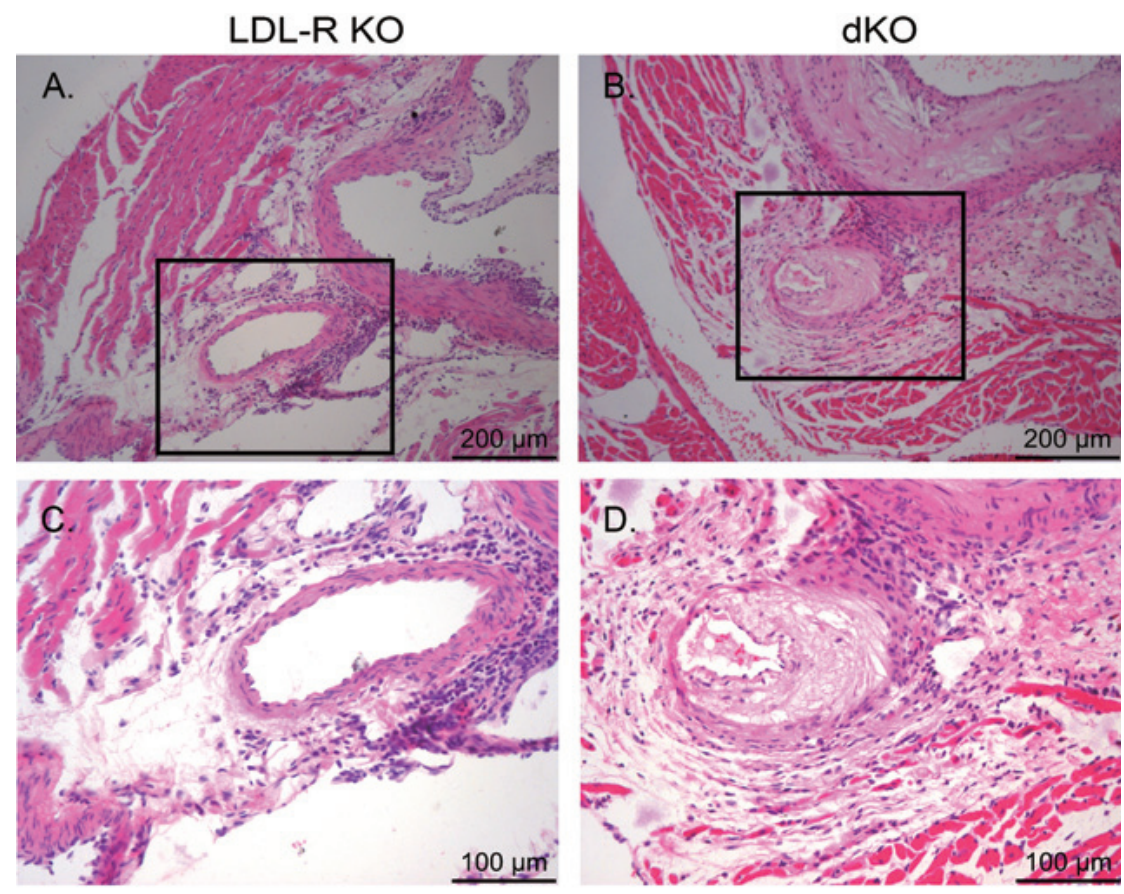

E. LDL-R KO
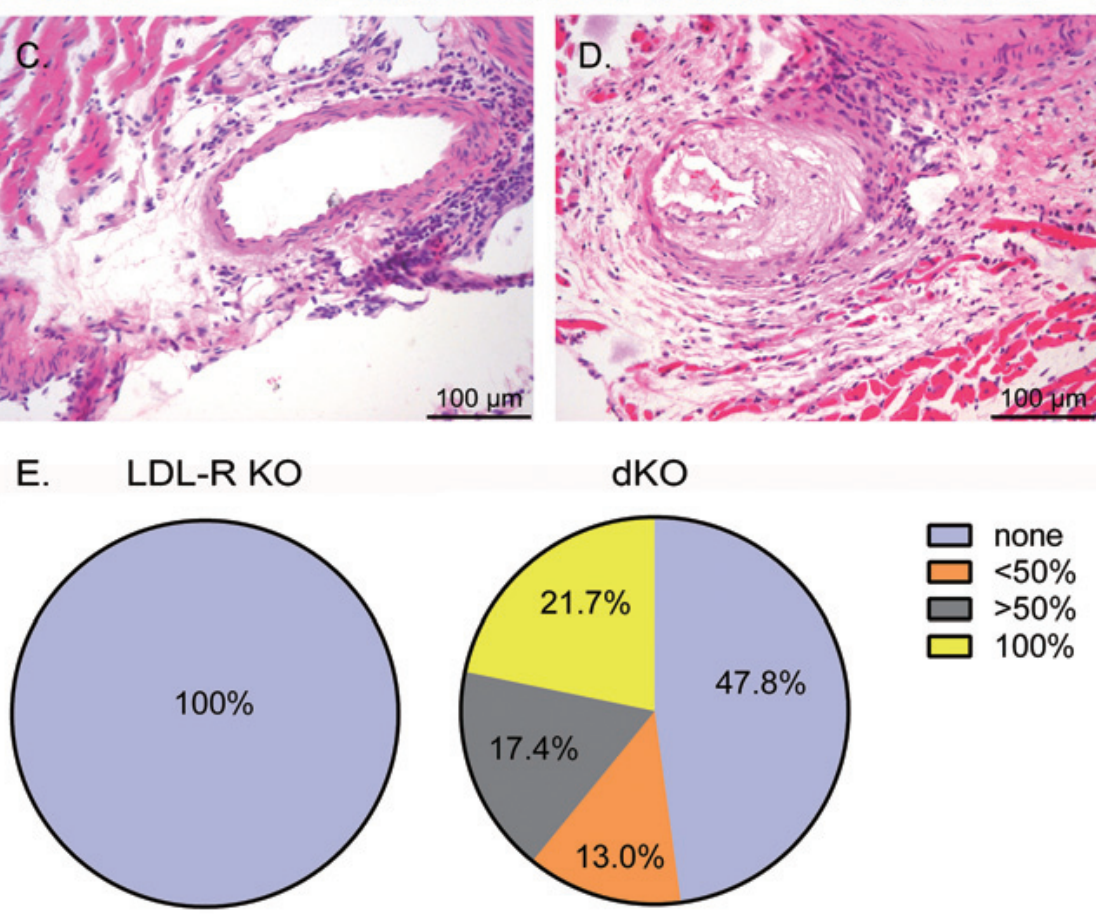

Coronary atherosclerosis at the aortic sinus level

F. LDL-R KO

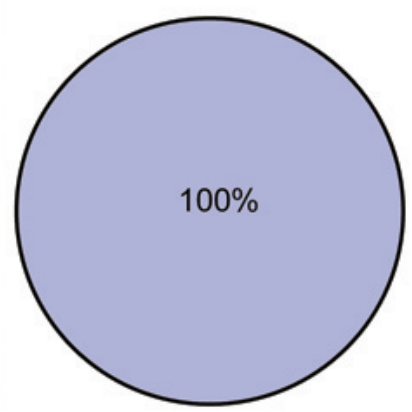

dKO

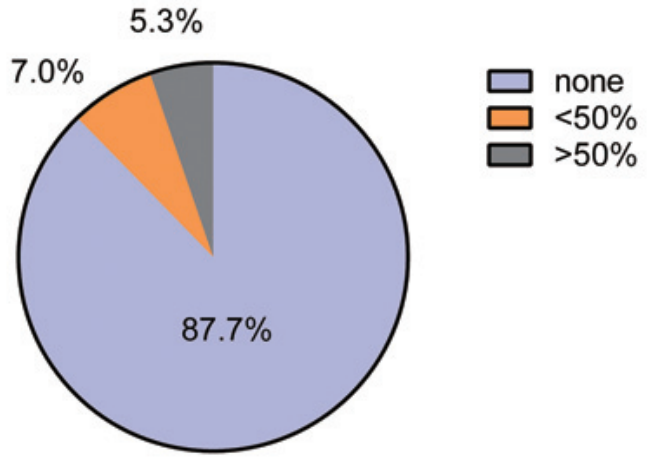

\section{Coronary atherosclerosis at the papillary muscle level}

Fig. 5. Analysis of CA in mice on the modified western-type diet (mWD) for 12 weeks

A-D: HE staining of coronary arteries at the aortic sinus level. The boxes in A and B indicated coronary arteries. C and D: Magnified views of the box areas in A and B, respectively. E: Quantitative analysis of CA at the aortic sinus level in mice on the mWD for 12 weeks. F: Quantitative analysis of CA at the papillary muscle level in mice on the $\mathrm{mWD}$ for 12 weeks. $n=7$ per group 

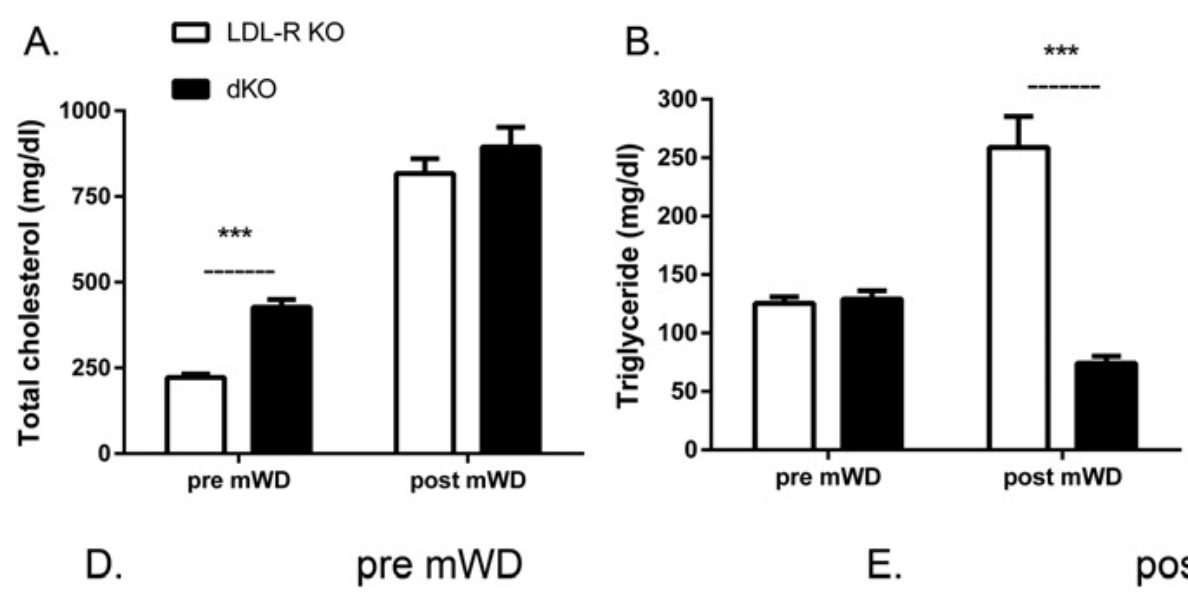

C.

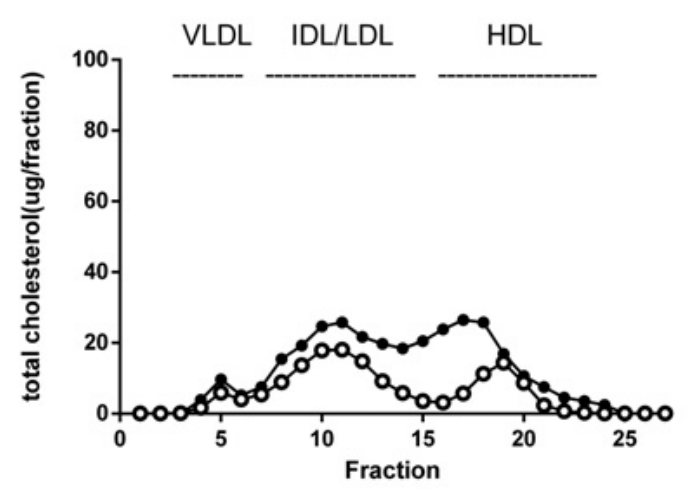

E. post mWD
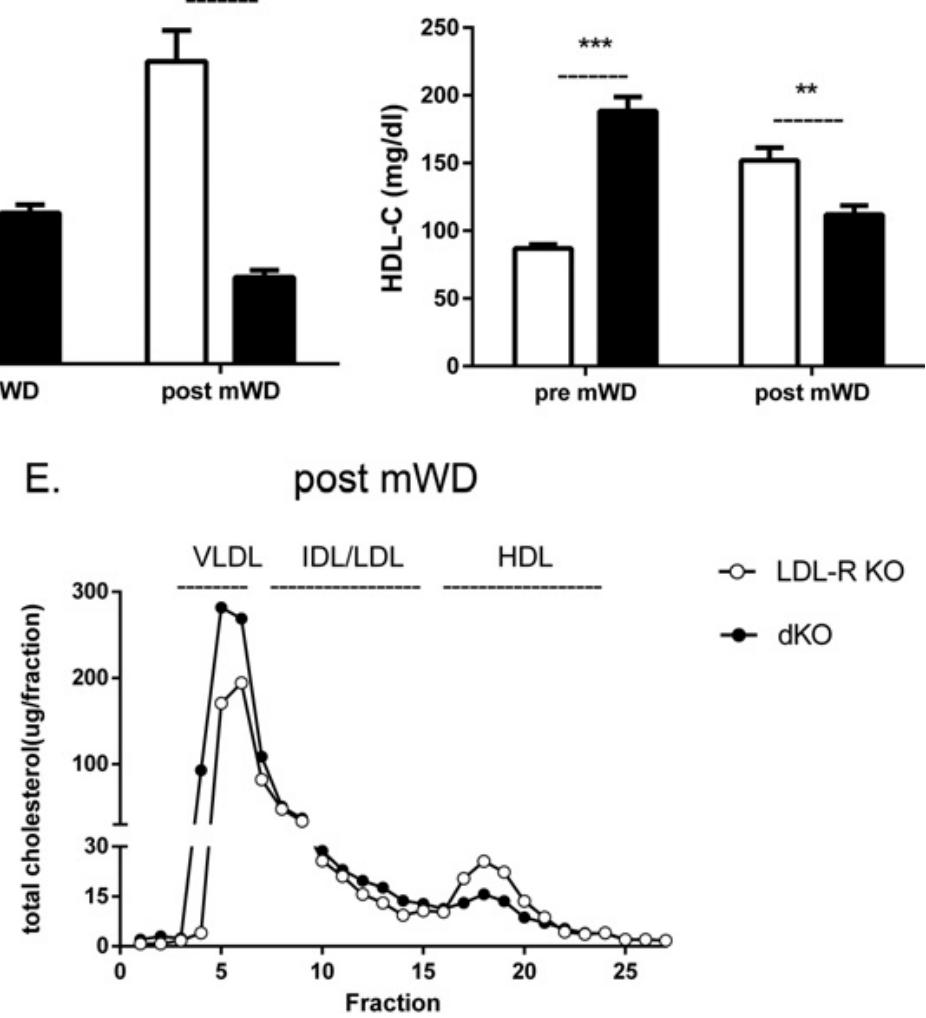

Fig. 6. Plasma lipids of mice before and after the modified western-type diet (mWD) feeding

A-C: Plasma TC (A), TG (B), and HDL-C (C) before and 12 weeks after the mWD feeding; D: Plasma cholesterol distribution by FPLC before the $\mathrm{mWD}$ feeding; E: Plasma cholesterol distribution by FPLC after the mWD feeding for 12 weeks. (Blank bar/dot: LDL-R KO mice; solid bar/dot: $\mathrm{dKO}$ mice)

**: $P<0.01$ vs. LDL-R KO mice; ${ }^{* * *}: P<0.001$ vs. LDL-R KO mice. $n=8-15$ per group

mWD: modified western-type diet; VLDL: very low density lipoprotein; IDL: intermediate density lipoprotein

diet also led to a significant increase of plasma TG in LDL-R KO mice (from $126 \pm 5.38 \mathrm{mg} / \mathrm{dl}$ to $259 \pm$ $26.6 \mathrm{mg} / \mathrm{dl}$ ), whereas it induced an unexpected decrease of plasma TG in $\mathrm{dKO}$ mice (from $129 \pm 6.88 \mathrm{mg} / \mathrm{dl}$ to $74.1 \pm 6.02 \mathrm{mg} / \mathrm{dl})$ (Fig. 6B).

\section{Discussion}

In this study, we increased the cholesterol content in the western-type diet from standard $0.15 \%$ to moderate $0.5 \%$. A higher plasma TC level (700-1000 $\mathrm{mg} / \mathrm{dl}$ ) was induced by the modified western-type diet than by the standard western-type diet $(500-750 \mathrm{mg} /$ $\mathrm{dl})$, and the modified western-type diet aggravated plaque development in LDL-R KO mice. When SR-BI/LDL-R dKO mice were fed this modified western-type diet, they developed CA and cardiac ischemia/infarction as indicated by ECG, SPECT, and myocardial TTC/Sirius red staining, along with heart dysfunction as indicated by Echo, suggesting the suc- cessful induction of diet-induced CA and IHD. While we were preparing this manuscript, Fuller et al also reported diet-induced $\mathrm{CA}$ and myocardial infarction in SR-BI/LDL-R dKO mice that were fed various atherogenic diets with high cholesterol, including Paigen diet $(1.25 \%$ cholesterol) with or without sodium cholate and pure high-cholesterol diet $(2 \% \text { cholesterol })^{14)}$. Altogether, our data demonstrated that SR-BI deficiency could lead to CA and IHD in LDL-R KO mice when challenged with the appropriate atherogenic diet. However, the mechanism by which SR-BI modulates the susceptibility of CA development in mice is still unknown. We found that the plaque composition in $\mathrm{dKO}$ mice was quite different from that in control LDL-R KO mice, for example, abnormal collagen accumulated in the atherosclerotic plaques, including coronary atherosclerotic plaques, in dKO mice (see Supplemental Fig. 1). It remains undefined whether SR-BI could interact with collagen metabolism and thus contribute to CA development. 
In this study, we observed that in SR-BI/LDL-R $\mathrm{dKO}$ mice, $\mathrm{CA}$ at the aortic sinus level was continuous to the lesion of the aortic sinus. To explore whether it was an extension of the aortic sinus lesions, we adopted a serial-section protocol from the aortic sinus level down to the papillary muscle level at an interval of $300 \mu \mathrm{m}$ to characterize the severity and spatial distribution of CA. We found that in the $\mathrm{dKO}$ mice fed the modified western-type diet for 12 weeks, CA was mainly at the aortic sinus level or in the common coronary artery as suggested by Weicheng et $a l^{7)}$, and much less was found in other levels. Instead, in the dKO mice that failed to survive an extended modified western-type diet feeding, obstructive CA could be found adjacent to the fibrotic myocardium and was not restricted at the aortic sinus level any more (see Supplemental Fig. 2). This suggests that hemodynamics might play an additional role in the progression of CA in SR-BI/LDL-R dKO mice.

Although the modified western-type diet increased plasma TC in SR-BI/LDL-R dKO mice, it significantly decreased plasma HDL-C. We hypothesized that the potential mechanisms of decreased HDL-C in $\mathrm{dKO}$ mice might be related to hemolysis/ anemia and splenomegaly ${ }^{15)}$, reminiscent of lecithin cholesterol acyl transferase (LCAT) deficient patients with syndromes closely associated with low HDL-C and the presence of $\mathrm{LpX}$, an abnormal lipoprotein particles enriched with free cholesterol. In fact, SR-BI deficiency has been reported to result in LCAT deficiency ${ }^{16,17)}$. However, this hypothesis needs further investigation.

Besides RCT, HDL particles exert many other anti-atherosclerotic and cardio-protective effects, such as anti-inflammation, anti-oxidation, anti-thrombosis, anti-apoptosis, and vasodilation ${ }^{18,19)}$. Deletion of the HDL receptor SR-BI, by changing the size and composition of HDL particles, disturbs the above biological functions of HDLs and even promotes the transformation of anti-atherosclerotic HDLs to pro-atherogenic HDLs, the so-called dysfunctional HDLs ${ }^{9}$. An increasing number of clinicians have realized that HDL dysfunction, rather than plasma HDL-C levels, might be an independent risk factor for cardiovascular disease, particularly pertaining to patients with normal plasma TC and LDL-cholesterol (LDL-C) and/or increased plasma HDL-C levels. Currently, mice with defects in LCAT, ABCA1, apoA1, and SR-BI have been reported to have dysfunctional HDLs ${ }^{20)}$. However, only atherosclerotic SR-BI deficient mice such as SR-BI/apoE dKO mice and SR-BI/LDL-R dKO mice developed CA and IHD, suggesting that these mice could be used as valuable tools to explore the relationship between HDL dysfunction and cardiovascular diseases and also to screen for potential therapeutic targets and drugs to improve HDL function. While $\mathrm{CA}$ and IHD in SR-BI/apoE $\mathrm{dKO}$ mice fed a chow diet and SR-BI/LDL-R dKO mice fed high cholesterol diets progressed too rapidly to allow heart remodeling, SR-BI/LDL-R dKO mice fed the modified westerntype diet with moderate cholesterol could survive with heart dysfunction. Thus, SR-BI/LDL-R dKO mice on the modified western-type diet could be used as a preferred murine model for studies on chronic cardiac ischemia/infarction and the progression of heart dysfunction to failure.

As stated in the introduction, the establishment of appropriate disease models serves the urgent needs to explore not only pathologic mechanisms of the disease onset and progression but also potential therapeutic solutions. For the latter, the development of highly effective evaluating systems is no less important than the establishment of the disease models itself. To date, several murine models of human IHD, including apoE/ LDL-R dKO mice ${ }^{21)}$, SR-BI/apoE dKO mice ${ }^{11,22)}$, SR-BI/LDL-R dKO mice ${ }^{14)}$, SR-BI KO/apoE $\mathrm{E}^{\text {mut }-1-}$ mice $^{23,24)}$, PDZK1/apoE dKO mice ${ }^{25)}$, eNOS/apoE dKO mice ${ }^{26)}, S R-u P A^{\text {tg }} / a p o E ~ K O ~ m_{c e}{ }^{27)}$, Akt1/apoE $\mathrm{dKO}$ mice $^{28)}$, and $\mathrm{Fbn}^{\mathrm{mut}^{+/}-/ \mathrm{apoE} \mathrm{KO} \text { mice }}{ }^{29)}$, have been established. Of these models, cardiac ischemia/ infarction was mainly evaluated by histological staining such as myocardial TTC staining and Masson staining. No sensitive and specific in vivo diagnostic approach has been developed in these models. Although SPECT has been widely used in clinical practice, in this study, we are the first to apply in vivo SPECT scanning to detect cardiac ischemia in a murine model of human IHD. Compared with coronary angiography, which cannot achieve a resolution high enough to obtain clear images in a fast-beating living mouse heart, SPECT is sensitive to not only the diagnosis of cardiac ischemia but also the in vivo evaluation of cardiac reperfusion. The combined use of SPECT and Echo, as demonstrated in this study, could provide not only in vivo evidence of the disease progression but also the effects of drug interventions on cardiac reperfusion and function in murine models of human IHD.

\section{Conclusion}

We demonstrated that SR-BI deletion led to CA and IHD in LDL-R KO mice that were fed the modified western-type diet. We have not only established SR-BI/LDL-R dKO mice as a diet-induced murine model of human IHD but have also provided an option of an effective in vivo evaluating system by the combined use of SPECT and Echo for cardio-protective drug discovery in established murine models of 
human IHD.

\section{Abbreviations}

ABCA1: ATP-binding cassette transporter 1; apo: apolipoprotein; CA: coronary atherosclerosis; $\mathrm{dKO}$ : double knockout; ECG: electrocardiography; Echo: echocardiography; EF: ejection fraction; FPLC: fast protein liquid chromatography; FS: fractional shortening; HDL: high-density lipoprotein; HDL-C: highdensity lipoprotein cholesterol; IHD: ischemic heart disease; KO: knockout; LCAT: lecithin cholesterol acyl transferase; LDL-C: low-density lipoprotein cholesterol; LDL-R: low-density lipoprotein receptor; LV: left ventricular; mWD: modified western-type diet; RCT: reverse cholesterol transport; SPECT: single photon emission computed tomography; SR-BI: scavenger receptor class B type 1; TC: total cholesterol; TG: triglycerides; TTC: 2,3,5-triphenyltetrazolium chloride; VLDL: very low-density lipoprotein

\section{Acknowledgements}

We gratefully thank Haiyi Yu and Rao Song for their technical assistance. We also gratefully thank Natural-Med Inc. for their kind provision of probucol to reverse the female infertility caused by SR-BI ablation $^{30)}$. This work is financially supported in part by a collaborative grant from Center for Molecular and Translational Medicine (BMU20140475), Major National Basic Research Program of the People's Republic of China (2011CB503900 and 2012CB517505), and National Natural Science Foundation of the People's Republic of China (81470553, 81270367 and 81470555).

\section{Conflict of Interest}

None declared.

\section{References}

1) http://www.who.int/healthinfo/statistics/mortality.

2) Plump AS, Smith JD, Hayek T, Aalto-Setala K, Walsh A, Verstuyft JG, Rubin EM and Breslow JL: Severe hypercholesterolemia and atherosclerosis in apolipoprotein E-deficient mice created by homologous recombination in ES cells. Cell, 1992; 71: 343-353

3) Zhang SH, Reddick RL, Piedrahita JA and Maeda N: Spontaneous hypercholesterolemia and arterial lesions in mice lacking apolipoprotein E. Science, 1992; 258: 468471

4) Ishibashi S, Brown MS, Goldstein JL, Gerard RD, Hammer RE and Herz J: Hypercholesterolemia in low density lipoprotein receptor knockout mice and its reversal by adenovirus-mediated gene delivery. J Clin Invest, 1993; 92: 883-893

5) Ishibashi S, Goldstein JL, Brown MS, Herz J and Burns DK: Massive xanthomatosis and atherosclerosis in cholesterol-fed low density lipoprotein receptor-negative mice. J Clin Invest, 1994; 93: 1885-1893

6) Nakashima Y, Plump AS, Raines EW, Breslow JL and Ross R: ApoE-deficient mice develop lesions of all phases of atherosclerosis throughout the arterial tree. Arterioscler Thromb, 1994; 14: 133-140

7) $\mathrm{Hu}$ W, Polinsky P, Sadoun E, Rosenfeld ME and Schwartz SM: Atherosclerotic lesions in the common coronary arteries of ApoE knockout mice. Cardiovasc Pathol, 2005; 14: $120-125$

8) Rigotti A, Trigatti B, Babitt J, Penman M, Xu S and Krieger M: Scavenger receptor BI--a cell surface receptor for high density lipoprotein. Curr Opin Lipidol, 1997; 8: 181-188

9) Trigatti B and Rigotti A: Scavenger receptor class B type I (SR-BI) and high-density lipoprotein metabolism: recent lessons from genetically manipulated mice. Int J Tissue React, 2000; 22: 29-37

10) Krieger $M$ and Kozarsky K: Influence of the HDL receptor SR-BI on atherosclerosis. Curr Opin Lipidol, 1999; 10: 491-497

11) Braun A, Trigatti BL, Post MJ, Sato K, Simons M, Edelberg JM, Rosenberg RD, Schrenzel $M$ and Krieger M: Loss of SR-BI expression leads to the early onset of occlusive atherosclerotic coronary artery disease, spontaneous myocardial infarctions, severe cardiac dysfunction, and premature death in apolipoprotein E-deficient mice. Circ Res, 2002; 90: 270-276

12) Covey SD, Krieger M, Wang W, Penman M and Trigatti BL: Scavenger receptor class B type I-mediated protection against atherosclerosis in LDL receptor-negative mice involves its expression in bone marrow-derived cells. Arterioscler Thromb Vasc Biol, 2003; 23: 1589-1594

13) Song K, Han Y, Zhang L, Liu G, Yang P, Cheng X, Bu L, Sheng $\mathrm{H}$ and Qu S: ATP Synthase beta-Chain Overexpression in SR-BI Knockout Mice Increases HDL Uptake and Reduces Plasma HDL Level. Int J Endocrinol, 2014; 2014: 356432

14) Fuller M, Dadoo O, Serkis V, Abutouk D, MacDonald M, Dhingani N, Macri J, Igdoura SA and Trigatti BL: The effects of diet on occlusive coronary artery atherosclerosis and myocardial infarction in scavenger receptor class $\mathrm{B}$, type $1 /$ low-density lipoprotein receptor double knockout mice. Arterioscler Thromb Vasc Biol, 2014; 34: 2394 2403

15) Liao J, Gao M, Wang M, Guo X, Huang W and Liu G: Spontaneous and diet-aggravated hemolysis and its correction by probucol in SR-BI knockout mice with LDL-R deficiency. Biochem Biophys Res Commun, 2015; 463: 48-53

16) El Bouhassani M, Gilibert S, Moreau M, Saint-Charles F, Treguier M, Poti F, Chapman MJ, Le Goff W, Lesnik P and Huby T: Cholesteryl ester transfer protein expression partially attenuates the adverse effects of SR-BI receptor deficiency on cholesterol metabolism and atherosclerosis. J Biol Chem, 2011; 286: 17227-17238

17) Thacker SG, Rousset X, Esmail S, Zarzour A, Jin X, Col- 
lins HL, Sampson M, Stonik J, Demosky S, Malide DA, Freeman L, Vaisman BL, Kruth HS, Adelman SJ and Remaley AT: Increased plasma cholesterol esterification by LCAT reduces diet-induced atherosclerosis in SR-BI knockout mice. J Lipid Res, 2015; 56: 1282-1295

18) Rye KA and Barter PJ: Cardioprotective functions of HDLs. J Lipid Res, 2014; 55: 168-179

19) Santos-Gallego CG, Badimon JJ and Rosenson RS: Beginning to understand high-density lipoproteins. Endocrinol Metab Clin North Am, 2014; 43: 913-947

20) Hoekstra M and Van Eck M: Mouse models of disturbed HDL metabolism. Handb Exp Pharmacol, 2015; 224: 301-336

21) Caligiuri G, Levy B, Pernow J, Thoren P and Hansson GK: Myocardial infarction mediated by endothelin receptor signaling in hypercholesterolemic mice. Proc Natl Acad Sci U S A, 1999; 96: 6920-6924

22) Braun A, Zhang S, Miettinen HE, Ebrahim S, Holm TM, Vasile E, Post MJ, Yoerger DM, Picard MH, Krieger JL, Andrews NC, Simons M and Krieger M: Probucol prevents early coronary heart disease and death in the highdensity lipoprotein receptor SR-BI/apolipoprotein E double knockout mouse. Proc Natl Acad Sci U S A, 2003; 100: 7283-7288

23) Zhang S, Picard MH, Vasile E, Zhu Y, Raffai RL, Weisgraber $\mathrm{KH}$ and Krieger M: Diet-induced occlusive coronary atherosclerosis, myocardial infarction, cardiac dysfunction, and premature death in scavenger receptor class B type I-deficient, hypomorphic apolipoprotein ER61 mice. Circulation, 2005; 111: 3457-3464

24) Nakaoka H, Nakagawa-Toyama Y, Nishida M, Okada T, Kawase R, Yamashita T, Yuasa-Kawase M, Nakatani K, Masuda D, Ohama T, Sonobe T, Shirai M, Komuro I and Yamashita S: Establishment of a novel murine model of ischemic cardiomyopathy with multiple diffuse coronary lesions. PLoS One, 2013; 8: e70755

25) Yesilaltay A, Daniels K, Pal R, Krieger M and Kocher O: Loss of PDZK1 causes coronary artery occlusion and myocardial infarction in Paigen diet-fed apolipoprotein E deficient mice. PLoS One, 2009; 4: e8103

26) Kuhlencordt PJ, Gyurko R, Han F, Scherrer-Crosbie M, Aretz TH, Hajjar R, Picard MH and Huang PL: Accelerated atherosclerosis, aortic aneurysm formation, and ischemic heart disease in apolipoprotein E/endothelial nitric oxide synthase double-knockout mice. Circulation, 2001; 104: 448-454

27) Cozen AE, Moriwaki H, Kremen M, DeYoung MB, Dichek HL, Slezicki KI, Young SG, Veniant $M$ and Dichek DA: Macrophage-targeted overexpression of urokinase causes accelerated atherosclerosis, coronary artery occlusions, and premature death. Circulation, 2004; 109: 2129-2135

28) Fernandez-Hernando C, Ackah E, Yu J, Suarez Y, Murata T, Iwakiri Y, Prendergast J, Miao RQ, Birnbaum MJ and Sessa WC: Loss of Akt1 leads to severe atherosclerosis and occlusive coronary artery disease. Cell Metab, 2007; 6: 446-457

29) Van der Donckt C, Van Herck JL, Schrijvers DM, Vanhoutte G, Verhoye M, Blockx I, Van Der Linden A, Bauters D, Lijnen HR, Sluimer JC, Roth L, Van Hove CE, Fransen P, Knaapen MW, Hervent AS, De Keulenaer GW, Bult H, Martinet W, Herman AG and De Meyer GR: Elastin fragmentation in atherosclerotic mice leads to intraplaque neovascularization, plaque rupture, myocardial infarction, stroke, and sudden death. Eur Heart J, 2015; 36: 1049-1058

30) Miettinen HE, Rayburn $\mathrm{H}$ and Krieger M: Abnormal lipoprotein metabolism and reversible female infertility in $\mathrm{HDL}$ receptor (SR-BI)-deficient mice. J Clin Invest, 2001; 108: 1717-1722 
Supplemental Table 1. Ingredients of the modified western-type diet.

\begin{tabular}{lr}
\hline \multicolumn{2}{c}{ Modified western-type diet } \\
\hline Cholesterol (\%) & 0.5 \\
Lard (\%) & 20 \\
Powdered murine chow (\%) & 79.5 \\
\hline \multicolumn{2}{c}{ Murine chow diet } \\
\hline Raw protein (g/100 g) & 23.8 \\
Raw fat $(\mathrm{g} / 100 \mathrm{~g})$ & 5.4 \\
Raw fiber $(\mathrm{g} / 100 \mathrm{~g})$ & 3.5 \\
Raw ash $(\mathrm{g} / 100 \mathrm{~g})$ & 6.8 \\
Moisture $(\%)$ & 9.0 \\
Calcium $(\%)$ & 1.24 \\
Phosphorus $(\%)$ & 1.08 \\
\hline
\end{tabular}




\section{LDL-R KO}
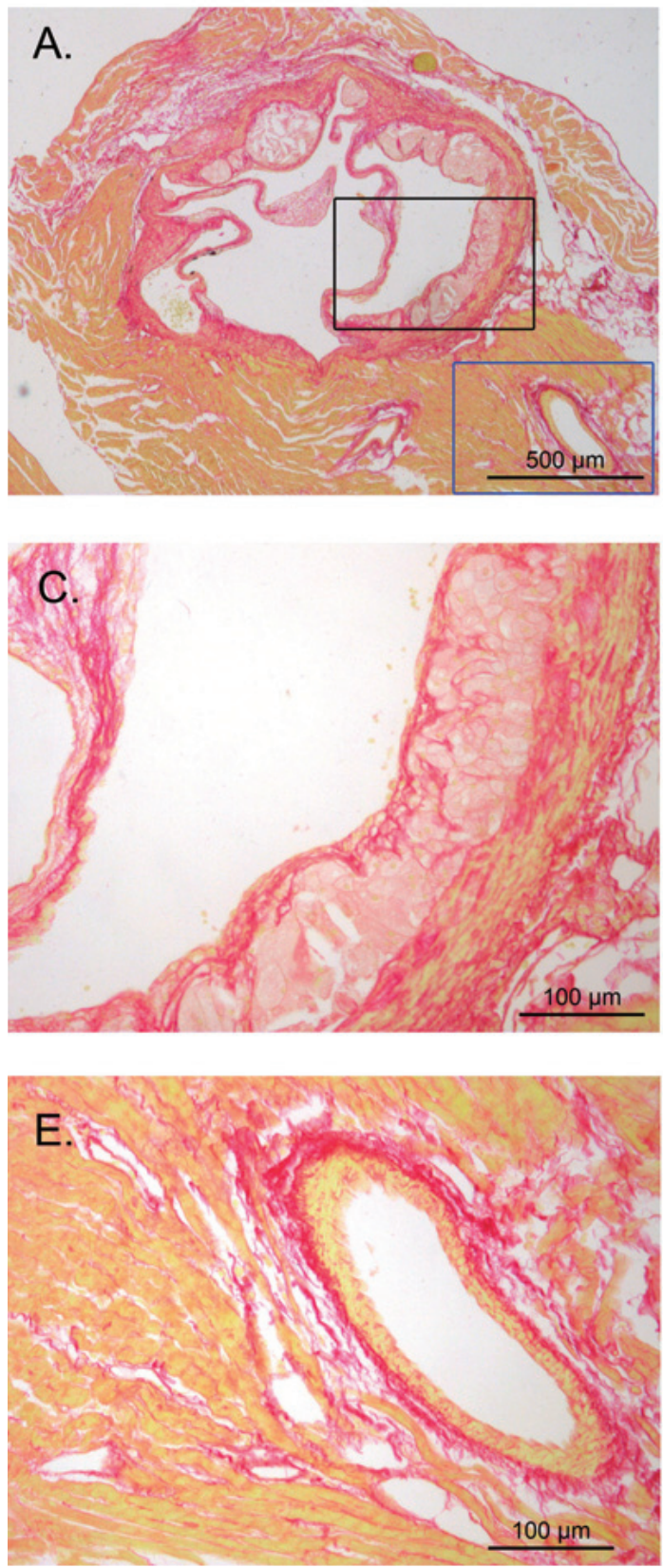

$\mathrm{dKO}$
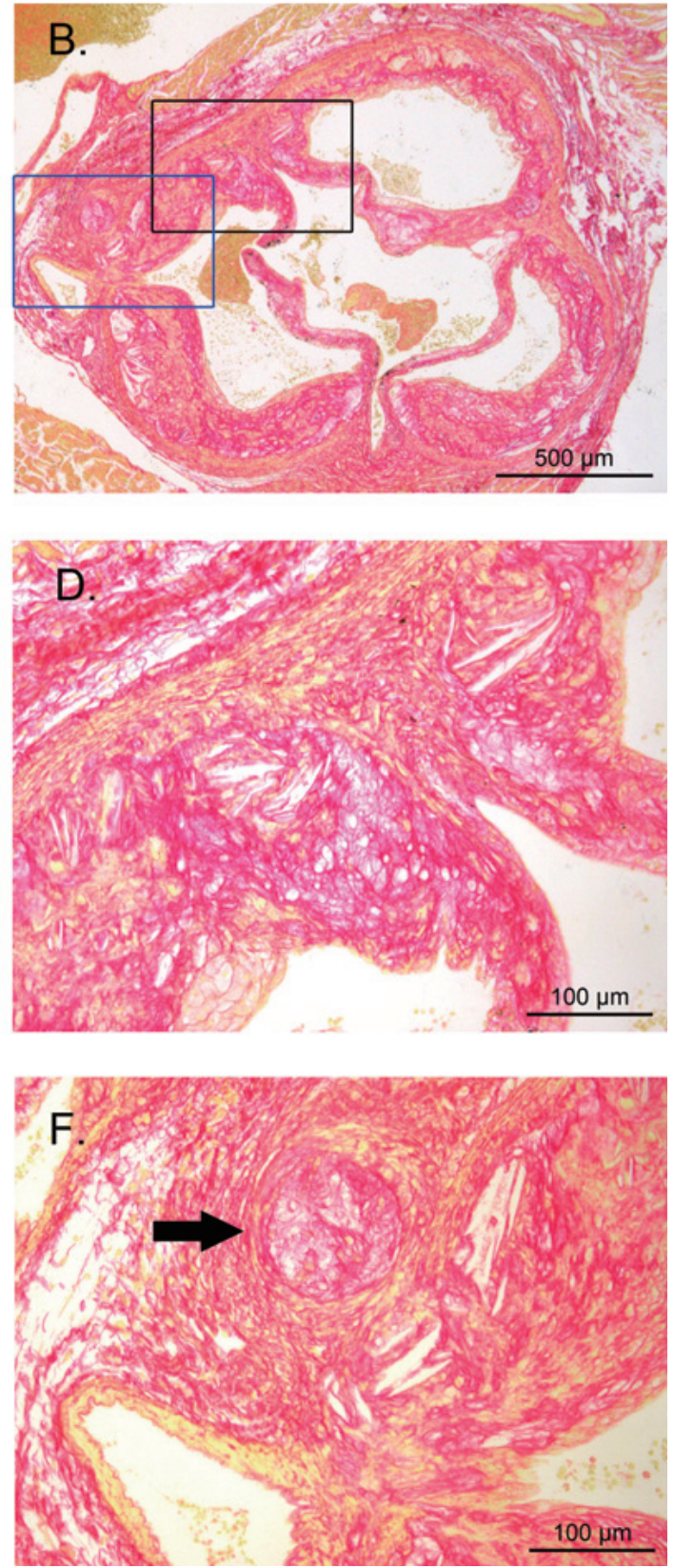

Supplemental Fig. 1. Sirius red staining of the atherosclerotic plaques at the aortic sinus level

A-B: Representative images obtained from LDL-R KO (A) and dKO mice (B) that were fed the modified westerntype diet (mWD) for 12 weeks. C-D: Magnified views of the black box areas in A and B, respectively, showing collagen in the atherosclerotic plaques of the aortic sinus. E-F: Magnified views of the blue box areas in A and B, respectively, showing collagen in the coronary atherosclerotic plaques. The arrow indicated an obstructive coronary artery. Collagen was stained red. 

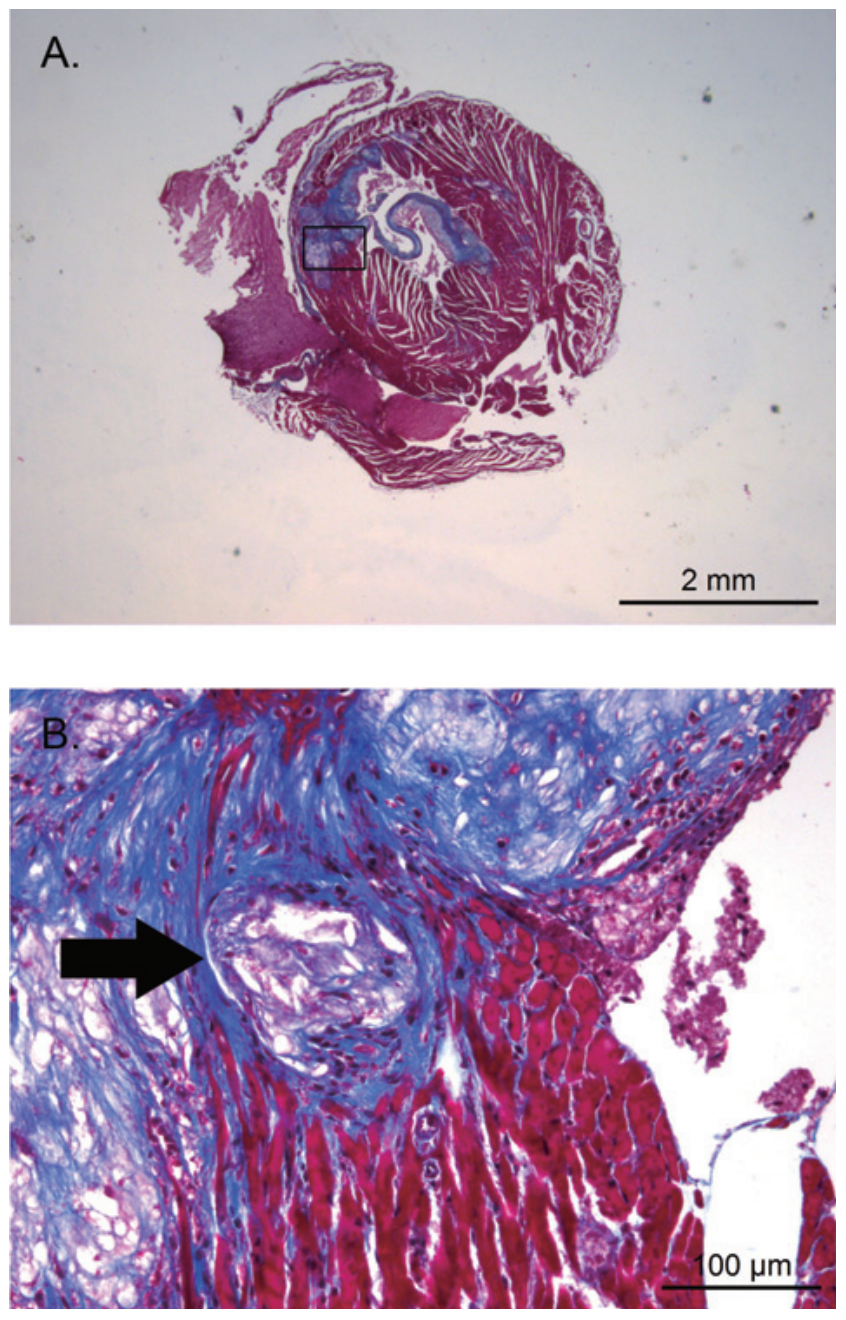

Supplemental Fig. 2. Masson-trichrome staining of the coronary atherosclerotic plaques at non-aortic sinus level.

A: A representative image obtained from dKO mice that died prematurely from the modified western-type diet $(\mathrm{mWD})$ feeding. B: Magnified views of the box areas in A. The arrow indicated an obstructive coronary artery. Normal myocardium was stained red while fibrotic tissues stained blue. 